\title{
Study on Construction Project Cost Risk Assessment System and
}

\section{Control Strategies}

\section{Li Jinxu ${ }^{1}$ \\ ${ }^{1}$ Chongqing Vocational Institute Engineering, Chongqing,China,402260}

Keywords: Construction Project, Cost Risk Assessment System, Control Strategies

\begin{abstract}
The construction project cost faces a lot of risks due to the ever-changing natural environment and social environment in the whole construction process. In order to minimize the risk of project construction cost, this paper gives the suggestions on rapid identification of risk, correct assessment of risk and reasonable prevention and control of risk to provide references for the relevant researchers.
\end{abstract}

\section{Introduction}

With the rapid development of China's economic construction, the construction projects are often large-scale and comprehensive. At the same time, it also has the characteristics of the concentrated investment, long cycle and so on. The construction enterprise faces the project cost risk also along with it. If we cannot correctly identify risks and develop a reasonable control measures, will seriously affect the construction of construction enterprises and economic benefits of the project. This requires construction enterprises must correctly identify the various stages of construction cost risk, the establishment of a system, the correct management measures. Project cost is a very tedious and complex thing which needs to take into account many risk factors. If you cannot make a correct analysis of the risk of engineering cost, the project cost will be increased, and even the project cannot be started. The cost risk management is to take the necessary measures to control these risks in order to achieve the ultimate goal in view of the engineering project risks.

\section{Risk Identification of Construction Project Cost Risk}

Construction project is different from other industries due to the large capital of the construction project. Therefore, in view of the construction project, because the capital investment is big, in the concrete construction, strengthens the cost control, especially the decision-making link, has the decisive influence to the project cost. It can be said that the construction enterprises in the construction process, with the risk of capital. Second, the complexity of risk. For construction project, mainly including installation, equipment structure, mechanical and electrical equipment etc. engineering, and construction units, government departments, auditors and other has direct contact, for the engineering valuation process and methods, has the characteristics of diversification, the existence of construction risk. For construction projects, due to the construction cycle is often longer, especially large construction projects, in the construction stage, very easy to be affected by the environment, so that the construction cost increases. At the same time, in the project cost and project decision-making process, we must strengthen the cost control, rational analysis and combing cost risk. In view of the construction cost, the size of the scale, often 
determines the cost, construction scale, cost is proportional to the relationship between the. In view of the construction scale, in the project cost has the reverse effect. In view of the construction project, because it is a kind of technical and public engineering construction. It attaches great importance to the economic benefits and social benefits. In the construction site, must be combined with geological and location conditions, considering the economic conditions, construction sites, clear construction sites and regions. If the construction site is not reasonable, it will increase the cost of the budget. In view of the construction project, the construction standard is very important, to the construction quality, cost control has the serious influence, the construction scale, the area, the standard, the technical standard and so on, all belong to the construction standard content. Therefore, the construction standards of the contents of the problem, will increase the cost of the project. Construction projects in investment, decision-making, usually in accordance with existing materials and the original standard, a reasonable estimate of project investment, construction, construction, production and other expenses for the total estimate. However, both the capital estimate and the construction estimate scope belong to the construction project cost control points.

\section{Risk Assessment of Construction Project Cost Risk Based on AHP}

Principles. In our daily life, many things are one-time but complex decision-making process. However, problems we face often do not have the available decision model to follow. It needs collecting large amounts of data for quantitative analysis. Therefore, some decision making it is hard to avoid with a certain degree of subjectivity and lack a rational and scientific. AHP (Analytic Hierarchy Process) method is a kind of quantitative and qualitative combination of multiple criteria decision making method. It provides a new, concise and practical modeling tool for the decision of such kind of problems. AHP method decomposes a complex problem into components, and the formation of hierarchical structure of the relationship. We use the comparison method to determine the relative importance of the decision-making program. In fact, the AHP method is to quantify the thinking process of experts, and it can be inconsistent with the experts' opinions through the consistency check. The quantitative research method based on the qualitative analysis not only maintains the integrity and consistency of our thought processes, and also improves our decision-making accurate and effective.

Steps. Expert scoring method is refers to anonymously consult the opinions of the experts, statistics of expert opinion, processing, analysis and induction, comprehensively and objectively most experts' experience and subjective judgment, of a large number of difficult to adopt techniques make a reasonable estimate, after several rounds of opinion consultation, feedback and adjustment, the problem of the analysis method of quantitative analysis of the factors. An average value of each comparison is obtained by means of the judgment matrix derived from the expert questionnaire, and finally the judgment matrix of the input of the model is obtained by using the average matrix as the input of the model. Through draw the eigenvalue, the CI, RI and CR is calculated. We compare CR with 0.1 . When the $\mathrm{CR}$ is less than 0.1 , the judgment matrix with satisfactory consistency, otherwise you'll need to adjust the judgment matrix, and make the satisfactory consistency. When the weights of we derive each factor in the risk model, we have to like level single sort of hierarchical ordering one-time inspection. When the CR we calculated is less than 0.1 , the overall level of the total order results are with satisfactory consistency. Otherwise you don't need to judge matrix element values.

The steps of the cost risk assessment of construction project based on AHP are as follows: 


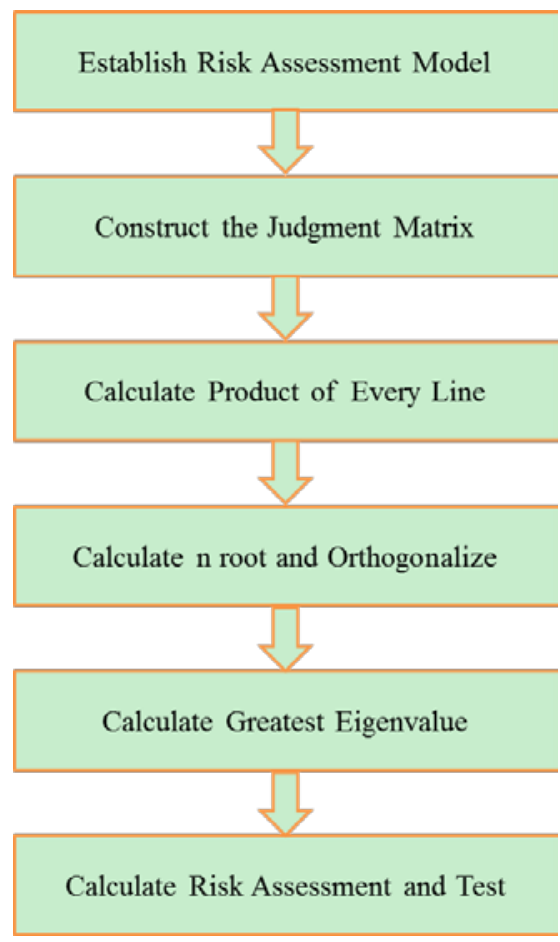

Figure 1. Steps of the cost risk assessment of construction project based on AHP

\section{Risk Control of Construction Project Cost Risk}

Positively Establish Risk Awareness. The success of the project bidding work is the basis for the successful completion of the project cost. Construction contractor should be necessary for the construction design drawings, engineering quantity list, tender required documents, legal contract terms and meet the market admittance of practical engineering according to existing conditions as complete as possible. From the perspective of construction enterprises, we must first fully understand the substance of the tender documents, and at the same time, in view of some of the problems raised in the paper may lead to the risk of problems. In the list price process, to avoid the risk in the first place, according to the strength of the enterprise itself and the specific circumstances of the market, the factors of the project analysis and analysis. At the same time, in the actual operation of the specific, adopt the unbalanced quotation for a specific project and to ensure price change to those expected quantities may increase, design drawings, vague can be appropriate to increase the unit price. On the contrary, we can lower the price as far as possible in the whole bidding process remain active. In the contract entered into prior to the logic of contract of rigor, regulation and the terms of the contract were carefully studied and determine the rights and obligations of the principle of reciprocity as a basis for, enter into a clear responsibility of the contract with the owners, fair and lawful rights and interests of their own. When the owners of the project cost, it is standing on the investment side of the project participation and consider the problem of; when the contractor in the process of engineering cost requirements increase the project cost, increase their profits, he needs to achieved a market supply as the main management objectives. From the different interests of the need to achieve the management objectives are different, in the management process to the project cost management content and methods to continuously enrich and improve. At the same time, we should also be involved in the scope of the risk described in detail to reduce the risk of contract terms.

Strictly Audit Investment Estimation. In view of the construction cost, the material cost control must be strengthened. The material consumption, the quota management and the quota 
management are strictly controlled. If there is an capital excessive problem, we must analyse the excess reason and make reasonable measures to correct the problem in time. For cost control, need to improve the construction process, reduce material consumption, the specific functions of the project analysis. In accordance with the material properties, select the lower price materials, thereby reducing the cost of materials. Simultaneously. According to the measurement and acceptance, the waste material can be recovered and the material consumption is reduced. In addition, we must strengthen artificially cost control, according to the amount of labor, the amount of labor, quota calculation, the technical level and production management level can be improved, and rational arrangement of construction labor, avoid invalid production, resulting in waste of engineering. For engineering construction, the use of new technologies, materials and processes, to promote the production cost and construction investment to reduce, to achieve maximum cost control. In view of the construction cost, the feasibility study must be strengthened in the project proposal preparation, including the market, the benefit and the technical research, and the establishment of the research report. Based on three research perspectives, market research can effectively solve the problem of product solutions and production scale.

Carefully Inspect Project Management. In the construction stage, the construction unit must strengthen contract management to strengthen project management and improve the management of the site to prevent the waste of investment. In the cost control decision, not only the project financial accounting personnel work, not only the project department, the finance department responsibility, is the task of all construction participants. In the cost control, it is necessary to achieve full participation, prompting all personnel to participate in cost control. At present, some construction enterprise engineering cost practitioners lack of adequate professional skills, lack of experience. Therefore, to enhance the contractor's claims management awareness is very necessary, especially during the construction phase, project claim need sufficient attention, the strict requirements of the construction progress and construction quality, to actively to design errors, changes in the quantities and construction drawings, and not natural conditions to respond, always will contract as the basis, to ensure the integrity of the data, and combined with the techniques of claim, the risk cost effectively resist. The construction phase of the risk control is an important link, in this process, the construction contractor should by strengthening project management, to include all aspects of the project quality, project payment, project claim management, the inspection and acceptance, and to avoid risk and strengthen the work. In the fierce market competition, the construction side can not sacrifice the quality of the project to exchange for low price competitiveness, which will bring the negative impact on the late stage of the construction for the contractor.

\section{Conclusion}

Construction project cost risk is an important aspect of engineering risk. It is thee management work that matters the whole process of the project and the interests of all construction personnel. We should learn to quickly identify the cost risk, correctly assess the cost risk and effectively control the cost risk of the construction project. Only in this way can we reduce the risk loss and improve the economic performance of the project construction.

\section{References}

[1] Fang Dexi, Yao Yuequn, Guangdong Building Materials, Vol. 29 (2013) No 1, p.88-90

[2] Sun Haihong, Ye Xiaoshu, Journal of Chongqing Jianzhu University, Vol. 27 (2005) No 6, 
p.121-126

[3] Sun Xuena, Urban construction theory Research, Vol. 6 (2016) No 8, p.1-2

[4] Wu Min, Construction Materials \& Decoration, Vol. 9 (2013) No 8, p.121-122 